\title{
Experimental economics : economic and game theoretic principles in experimental research in the social sciences
}

Citation for published version (APA):

Riedl, A. M. (2012). Experimental economics : economic and game theoretic principles in experimental research in the social sciences. METEOR, Maastricht University School of Business and Economics. METEOR Research Memorandum No. 001 https://doi.org/10.26481/umamet.2012001

Document status and date:

Published: 01/01/2012

DOI:

10.26481/umamet.2012001

Document Version:

Publisher's PDF, also known as Version of record

Please check the document version of this publication:

- A submitted manuscript is the version of the article upon submission and before peer-review. There can be important differences between the submitted version and the official published version of record.

People interested in the research are advised to contact the author for the final version of the publication, or visit the DOI to the publisher's website.

- The final author version and the galley proof are versions of the publication after peer review.

- The final published version features the final layout of the paper including the volume, issue and page numbers.

Link to publication

\footnotetext{
General rights rights.

- You may freely distribute the URL identifying the publication in the public portal. please follow below link for the End User Agreement:

www.umlib.nl/taverne-license

Take down policy

If you believe that this document breaches copyright please contact us at:

repository@maastrichtuniversity.nl

providing details and we will investigate your claim.
}

Copyright and moral rights for the publications made accessible in the public portal are retained by the authors and/or other copyright owners and it is a condition of accessing publications that users recognise and abide by the legal requirements associated with these

- Users may download and print one copy of any publication from the public portal for the purpose of private study or research.

- You may not further distribute the material or use it for any profit-making activity or commercial gain

If the publication is distributed under the terms of Article $25 \mathrm{fa}$ of the Dutch Copyright Act, indicated by the "Taverne" license above, 
Arno Riedl

Experimental Economics:

Economic and Game Theoretic

Principles in Experimental

Research in the Social Sciences

RM/12/001

\section{METEOR}

Maastricht University School of Business and Economics

Maastricht Research School of Economics

of Technology and Organization

P.O. Box 616

NL - 6200 MD Maastricht

The Netherlands 


\title{
Experimental Economics: \\ Economic and Game Theoretic Principles in Experimental Research in the Social Sciences
}

\author{
Arno Riedl ${ }^{*}$
}

December 20, 2011

\begin{abstract}
Understanding individual and social decisions and how they are affected by the environment and institutional constraints is at the heart of the the social sciences. With the exception of psychology, traditionally in the social sciences empirical evidence is gathered via happenstance data. Such data are plagued with endogeneity problems and unobserved variables which make it difficult to draw causal inferences and reliably test theories. In the last thirty years laboratory experiments are increasingly adopted, especially in economics. Experimental economics research is often based on formal economic or game theoretical models with clear-cut rules which allow unambiguous inferences from changes in environmental variables. This model-based approach is tightly linked to two principles of experimental economics: the use of task related (monetary) incentives and the proscription of deception. Experimental economics plays an important role in theory and model falsification as well as in digging up behavioral regularities in individual and interactive decision making. Research in experimental economics was instrumental in the development of new models of other-regarding preferences, boundedly rational reasoning, adaptive learning, and 'noisy' equilibrium models. The toolbox of economics experiments informs research in decision neuroscience and is also applied in many other fields of the social sciences. Undoubtedly, experimental economics will continue to challenge newly emerging models and suggest new theories of human behavior and keep on to significantly contribute to knowledge in the social sciences.
\end{abstract}

Keywords: experimental economics, methodology, no deception, incentives, game theory JEL codes: C7, C9, D03, D87

*Arno Riedl: CESifo, IZA, Netspar, and Maastricht University, Department of Economics (AE1), P.O. Box 616, 6200 MD Maastricht, the Netherlands, a.riedl@maastrichtuniversity.nl. 


\section{INTRODUCTION}

Experimental economics applies experimental methods, utilizing economic and game theoretic principles, to study individual and social decision situations that are of economic and social interest. Until the 1980s economics was considered a non-experimental science and the few experimental studies that had been carried out were largely ignored by the economic profession as well as the other social sciences. Since then, however, experimental economics research is on the rise and the number of publications in peer-reviewed journals is growing exponentially. Nowadays, a search using the terms experimental economics returns about 31200 hits on Google Scholar. This is clear evidence for the success of the field but also makes it impossible to provide a comprehensive review of the whole field here.

Therefore, the following set-up is chosen. First, a brief history is given of research that could be subsumed under the term experimental economics, spanning from the 18th century until today. Second, two axioms of the experimental economics research method, which distinguishes it from most experiments in the other social sciences, especially psychology, are presented and discussed: the use of task related (monetary) incentives and the norm of not deceiving experimental subject. It is argued that these axioms are implied by the widespread good practice in experimental economics to implement (formal) economic or game theoretic models in the experimental laboratory and to use these models to predict outcomes. Third, the important role experimental economics played and is playing in theory testing and theory suggesting is discussed using three different sets of experiments and games. In this way some of the important key aspects of experimental economics are highlighted.

\section{A BRIEF HISTORY - FROM NON-EXPERIMENTAL TO EXPERIMENTAL SCIENCE}

According to Alvin E. Roth, the beginning of experimental economics could be placed in the eighteenth century, when the Bernoulli brothers applied a (quasi-)experimental method to decision problems under risk (reference ${ }^{1}$ (chapter 1$)$ ). Specifically, it is reported that Nicholas Bernoulli tried out the "St. Petersburg Gamble" $\underline{\underline{2}}$ as a hypothetical exercise on fellow mathematicians. This is a gamble where a fair coin is tossed until head shows up. The earnings depend on the number of trials needed for this to happen. In a popular version the earnings are parameterized in the following way: if the winning side is scored on the first trial earnings are USD 2, if scored on the second trial USD 4 , if scored on the $n$-th trial USD $2^{n}$. Since this happens with probabilities $1 / 2,1 / 4,1 / 2^{n}$, respectively, the expected earnings are the infinite sum of 1 's, that is, infinity. Perhaps not surprisingly, Bernoulli's fellows were not willing to pay an infinite sum of money for 
participating in this gamble. Besides the historical accounts and despite the age and prominence of the St. Petersburg problem, documented controlled experimental tests of the problem are scarce. The few available studies ${ }^{3}-\underline{\underline{5}}$, however, conform to the folk wisdom that people are rarely willing to pay more than USD 4 for playing the gamble ${ }^{6}$. Puzzled by the discrepancy between the expected value and the intuitive upper bound people would and should be willing to pay, the Bernoulli's developed a pre-version of expected utility with decreasing marginal utility. That is they introduced risk aversion into decision theory. Therefore, the hypothetical St. Petersburg experiment may be regarded as a first instance where experimental results were informative for theory building in the social sciences. This also relates to the important role of experimental economics as theory suggesting, which will be exemplified with more examples below.

Bardsley et al. identify philosopher David Hume as "another candidate for the experimental economist's Hall of Fame" (reference ${ }^{7}$, p.4) because he suggested the use of experiments for a better understanding of human ideas and reasonings. Other early accounts of influence of experimental findings on economic thinking can be found in the work of the pioneers of neoclassical economic theory and the marginal revolution in economics ${ }^{8.9}$. Their ideas were inspired by the diminishing marginal relationship between stimuli and sensations identified in early experimental studies in psychology (reference $\stackrel{7}{-}$, p. 5 ).

Despite these early accounts that experiments can produce useful and informative results for social sciences research and, in particular, economics, it was considered a non-experimental science for the largest part of the twentieth century. Such skepticism regarding the experimental method was also prevailing in related social sciences, as sociology and political science, where individual decisions and aggregate outcomes are shaped by (social) interaction. Generally, it was thought to be impossible to artificially create environments - in the laboratory or the field - that could reflect politically, socially, or economically relevant factors in a way that could generate scientifically sound and societally and economically relevant results. Economics, in particular, was assumed to be doomed to rely on observations collected in naturally occurring situations or on happenstance data generated by (un)intended natural experiments. This predominant view is frequently illustrated by a quote of the 1976 Nobel laureate in economic science Milton Friedman who wrote in 1953: "Unfortunately, we can seldom test particular predictions in the social sciences by experiments explicitly designed to eliminate what are judged to be the most important disturbing influences. Generally, we must rely on evidence cast up by the 'experiments' that happen to occur." (reference $\frac{10}{}$, p.10). Most prominent economists (see, e.g., reference 11 ) held a similar view up to the mid-eighties of the last century, thereby expressing the attitude of the overwhelming majority of active researchers in economics and the social sci- 
ences at this time. Some still hold this denying view $\underline{12}$, while others have radically changed their opinion already in the 1990's by attesting experimental economics to be an "exciting new development." (reference $\underline{13}$, p.5).

The first 'modern type' economics experiments were conducted in the 1930's by psychophysicist Thurstone $\underline{14}$ which were published in a psychology journal. The publication of an economics experiment in a leading economics journal did not occur before 1948 when Edward H. Chamberlain published his test on whether markets work efficiently $\underline{\underline{15}}$, which was largely ignored by the community, however. Nevertheless, in the 1950s and 1960s publications of lab experiments in economic journals witnessed a slow growth $\underline{16}-19$ that strongly accelerated later, especially

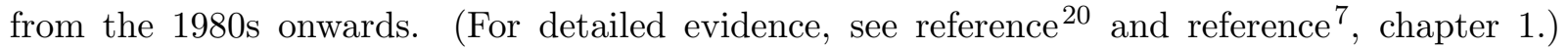
The significance of economics experiments was publicly recognized at the beginning of the 21st century with awarding the Nobel prize in economic sciences 2002 to Vernon Smith "for having established laboratory experiments as a tool in empirical economic analysis" who shared the prize with psychologist Daniel Kahneman "for having integrated insights from psychological research into economic science" $\underline{21}$. A second important recognition for the use of economics experiments in not only economics but also political science constitutes the Nobel prize in economic sciences 2009 awarded to Elinor Ostrom who uses experiments in many of her studies on the governance of the commons ${ }^{22,23}$. Nowadays the methods and tools of experimental economics are widely accepted in the social sciences and its success in terms of delivering new insights for economics and beyond undeniable.

\section{PRINCIPLES IN EXPERIMENTAL ECONOMICS}

Traditionally research in economics is a strongly driven by theory and formal modeling. This tradition also echoes in experimental economics in, for instance, the fact that many of the pioneers of experimental economics are theorists by training. Moreover, and more importantly, it is common practice in experimental economics to implement experimental designs (aka as 'paradigms' in experimental psychology) that closely resemble (game) theoretical models. The closeness of resemblance differs across experiments but it is fair to say that being theory- or model-based unites a large class of economics experiments.

\subsection{The use of monetary incentives}

Metaphorically speaking, an economics experiment is an economic decision situation or game that materializes in the laboratory. However, theoretical models are abstract and economic decision situations are real in the sense that real people make real decisions and real payoffs 
and earnings are implicated ${ }^{24}$. Therefore, an important problem to be solved is how one can translate an abstract model into a real laboratory decision situation. The solution to this problem is provided by Vernon Smith's induced values theory. $\underline{25}$ The theory can be illustrated in the framework of a classical market experiment testing the predictive power of the competitive theory of supply and demand. In such an experiment buyers and sellers 'meet' on an anonymous market to trade goods at mutual benefit. In the laboratory buyers and sellers are students and the goods to be traded are, for instance, red and blue paper strips, which are intrinsically worthless. One task of the experimenter is to induce value into the paper strips. In addition, since competitive market theory is silent about other elements that may influence trading behavior, like mood, boredom or fun from experiment participation, envy and fairness regarding the other participants, etc., the experimenter needs to have control over the subjects' preferences. That is, the homegrown preferences subjects bring to the laboratory must be neutralized and the new induced preferences should be the sole (or at least most important) motivation for trading paper strips. To achieve this, a reward medium, usually money, $m=m_{0}+\Delta m$ is introduced, where $m_{0}$ subsumes a subject's wealth net of the money received in the experiment, which is given by $\Delta m$. A subject's unobservable preferences can be denoted by a function $V\left(m_{0}+\Delta m, z\right)$ where $z$ stands for all elements save money a subject may derive (dis)utility from. To achieve control over a subject's preferences the experimenter has to guarantee that three assumptions are satisfied. (1) Monotonicity: everything else equal, subjects always prefer more over less money $m$. That is, the marginal utility of money $\partial V / \partial m$ is strictly positive for all feasible combinations of $(m, z)$. (2) Salience: the monetary earnings $\Delta m$ of a subject received in the experiment depend on the decisions of the subject. That is, earnings in the experiment are not a flat fee but task related. (3) Dominance: any changes in a subject's unobserved utility from decisions in the experiment stems predominantly from the change in money income $\Delta m$. That is, the influence of the unobservable other elements $z$ in the utility function on behavior in the experiment are negligible.

To see that under these assumptions the experimenter can indeed induce preferences over red and blue paper strips, consider that subjects in the experiment are paid according to their final holdings of red paper strips, $x$, and blue paper strips, $y$. (This example is a version of the example in reference 26 .) The experimenter wants to induce a utility function $U(x, y)$ which is represented by the subject's reward matrix $R(x, y)=\Delta m$. Hence, a subject's true unobserved preferences are represented by $V\left(m_{0}+\Delta m, z\right)=V\left(m_{0}+U(x, y), z\right)$. In order to induce the utility function $U(x, y)$ it needs to be satisfied that the marginal trade-off between $x$ and $y$ are the same for $V(x, y)$ and $U(x, y)$, because then and only then $R(x, y)$ overwrites the subject's homegrown preferences and choices between red and blue paper strips depend only on the induced utility function $U(x, y)$. To show that the marginal trade-offs are indeed the same it is necessary and 
sufficient to show that the marginal rate of substitutions ( $M R S)$ between $x$ and $y$, that is the ratio of marginal utilities between $x$ and $y$, are the same for $V$ and $U$ :

$$
M R S_{x, y}^{V}=\frac{\frac{\partial V}{\partial x}}{\frac{\partial V}{\partial y}}=\frac{\frac{\partial V}{\partial m} \frac{\partial U}{\partial x}+\frac{\partial V}{\partial z} \frac{\partial z}{\partial x}}{\frac{\partial V}{\partial m} \frac{\partial U}{\partial y}+\frac{\partial V}{\partial z} \frac{\partial z}{\partial y}}=\frac{\frac{\partial V}{\partial m} \frac{\partial U}{\partial x}}{\frac{\partial V}{\partial m} \frac{\partial U}{\partial y}}=\frac{\frac{\partial U}{\partial x}}{\frac{\partial U}{\partial y}}=M R S_{x, y}^{U}
$$

The first equality sign is the definition of the $M R S$ between $x$ and $y$ for utility function $V$. The second equality holds because saliency guarantees that $\partial U / \partial x$ and $\partial U / \partial y$ are not zero. The third equation holds by approximation because of dominance, $\partial z / \partial x \approx \partial z / \partial y \approx 0$. The fourth equation is obtained through monotonicity, $\partial V / \partial m>0$, and the fifth is again the definition of the $M R S$ between $x$ and $y$, now for utility function $U$.

The first two assumptions of induced values theory are easily satisfied. Everything else equal, there are not many people who dislike to have more money and saliency is controlled by the experimenter. The third assumption, however, may be problematic if, for instance, subjects take the earnings of others into account. This potential problematic of earnings comparisons or fairness considerations for induced values theory was also recognized by Smith himself. He argues, though, that it can be easily avoided by "the experimental condition of 'incomplete information'"(reference $\frac{25}{}$, p.278). That is, by not informing subjects about the earnings contingencies of other subjects. This solution is indeed successfully used in experimental market experiments where prices and quantities converge faster to the predicted competitive equilibrium with incomplete than with complete information about earnings contingencies 27 . Yet, this is not an overall solution because in many interesting situations people know each others earnings contingencies and often even each others actual earnings. Yet, the potential weakness of the third assumption turns out to be an actual strength. In fact, it allows researchers who are interested in people's social motivations, which are comprised in the variable $z$, to use monetary rewards to test the strength of these motivations by changing the monetary trade-off between ones own earnings and the earnings of others. Andreoni and Miller 28 , for instance, exploit this possibility in order to construct, test, and estimate people's preferences for altruism. Their starting pointing is the well-known dictator game $\underline{29}-\underline{31}$, where one subject, the dictator, can share or not money with another subject, the recipient. If the dictator is a rational selfish money maximizer she should keep all and give nothing. This is not observed, however. In shares of the total amount to be allocated, the dictator's average allocations to the recipient varies between 10 and 52 percent, and the frequency of (near) equal splits varies between 4 and 44 percent, mainly depending on the strength of anonymity between dictator, recipient and experimenter (Table 2.4 in reference 32 ). Two interesting studies challenge the interpretation that giving in dictator games reflects altruistic preferences or a taste for fairness by pointing out that framing or experimenter demand effects may explain some of the seemingly altruistic behavior $\underline{33,34}$. 
Andreoni and Miller ${ }^{28}$ modify the standard dictator game experiment in two ways. First, they vary the amount to be allocated across different decisions within subjects. Second, while in the standard dictator game one unit of money kept has the same value to the dictator as one unit of money given has to the recipient, this relative value of money kept and money given varies in the modified game. For instance, in one variation one unit kept is worth USD 1 to the dictator but one unit given is worth USD 4 to the recipient. These variations in the amount to be allocated and the relative value of keep and give have the same interpretation as variations in the budget constraint and relative prices of goods in consumption choice. In the experiment the dictator's 'consumption' choice is between own earnings and earnings of the recipient. In this framework one can utilize the axioms of revealed preferences 35 to construct preferences that are consistent with the observed choices. Using this approach the authors find that almost 100 percent of the participants' preferences obey to basic principles of rational decision theory or are, as the authors call it, rationally altruistic. Yet, being rational does not necessarily mean being selfishly money maximizing. In fact, only about a quarter of the subjects are strictly selfish money maximizers, the rest exhibits altruistic preferences at different degrees. In addition, about one-quarter of the subjects have preferences consistent with jealousy or spite. Other studies have also exploited the apparent 'weakness' of the third assumption of induced values theory to measure social or otherregarding and found that many people have a preference for efficiency $\underline{36}$ but also that mixed motives could be important $\frac{37}{\text {. }}$. (For a survey on dictator game and other allocation experiments, see reference $\frac{38}{3}$.)

From such and other research it appears that the use of task related incentives has some clear advantages over purely hypothetical scenarios. The fact that almost all published experimental economics studies use task related incentives also indicates that there is a large agreement among economists that saliency is considered to be an important design feature of economics experiments. Indeed, studies show that behavior differs between experiments with and without task related incentives. For instance, data generated without monetary incentives tend to exhibit more noise ${ }^{39}$ and with money at stake people are less generous than when generosity is hypothetical $^{29}$. However, whether this implies that extrinsic monetary incentives are generally to be favored over no such incentives is a matter of debate not only between economists and psychologists $\underline{40}$ but also among economists ${ }^{\underline{7}}$.

\subsection{The norm of no deception}

In experimental economics there is a strong norm against the use of deception, defined as actively misleading experimental subjects. Although nowhere formally formulated, the norm of no deception is so strong that it is basically impossible to publish an experimental study where the 
norm is perceived to be violated in any peer-reviewed economics journal. In 2001, Hertwig and Ortmann ${ }^{40}$ estimated that only 0.17 out of 10 published experiments used deception and it is likely that this number is even smaller now.

The proposition that deception should not be used in experiments rests on two axioms. First, that trust between experimental subjects and the experimenter is fundamental for having control over an experimental setting. Experimental economics designs often implement a game or decision situation with clear rules, where it is important, in order to draw accurate inferences, that subjects understand and believe the rules, inclusive the implied consequences for earnings. The discussed modified dictator game can serve as an example. Among other things, the researchers were interested in the price effect on revealed altruism. A hypothesis was that, if it is relatively more costly to be generous, dictators will be less willing to give money to the recipient. If one observes instead that a subject shares 50:50 irrespective of the relative price of giving money away, one can conclude that this subject's preferences over own earning and other earnings are close to perfect complements. Such a conclusion could not be drawn if one would have to doubt that the subject believes that her decisions will have the consequences described by the rules of the experiment. Indeed, if a subject believes that her choices do not have real consequences or that the real consequences are different from those described by the rules of the experiment the researcher cannot draw any conclusion from any observed choice. Hence, as long as one is not interested in behavior of subjects in situations where the experimenter knows that the subject knows or suspects to be deceived, deception seems not to be a good design choice.

This leads to the second axiom, namely that deception produces a negative externality for the scientific community. The practice of deception and debriefing in some social sciences implies that the knowledge of the practice of deception can and most likely will spread in the potential subject pool. Hence, even if a researcher herself does not deceive, the fact that others deceive can undermine subjects' confidence and trust and in consequence the researchers inferences from the data. Given that in practice many subjects are students the importance and speed of the spread of knowledge of deceptive practices should not be underestimated. In addition, with the increasing popularization of science via mass media the practice of deception may also spread further among the general population, which may also impede inferences from experiments with more representative subject pools. For most (if not all) experimental economists the externality argument together with the necessity of controlling the experimental setting, perhaps combined with the sanctioning mechanism of having difficulties to publish a paper that violates the norm, is sufficient for subscribing to the no deception norm. In fact, there is the additional argument that the use of deception is likely only myopically optimal, because a deceiving experimenter may undermine the validity of her own future research. 
An obvious problem in the discussion regarding the no deception norm is to find clean evidence that deception indeed has the presumed negative consequences. On the one hand, one cannot draw conclusive inferences from data that were generated using deception because either the data are already contaminated or no control conditions are available. (See reference $\underline{\underline{41}}$ for a meta-analysis approach to the estimation of the costs of deception.) On the other hand, it is difficult to conduct a controlled experiment on the effect of deception without actually deceiving subjects. An exceptional study achieving the latter with the least possible damage for the scientific community is reported in reference ${ }^{42}$. There it is shown that, in comparison to subjects who have not been deceived, deceived and debriefed subjects have a lower return rate to future experiments and also differ in their behavior. The authors conclude that their data provide qualified support for the proscription of deception.

\section{THE INTERPLAY BETWEEN RIGOROUS THEORETI- CAL MODELING AND EXPERIMENTAL EVIDENCE}

There are to fundamental but interrelated ways of thinking about the usefulness of economics experiment. One is that experimental economics is useful for testing theories. The other is that economics experiments can be used for "searching for facts" $\underline{43}$, that is, identifying and refining behavioral regularities. The latter aspect can feedback into the former as such identified regularities can inform theoretical reasoning and lead to new theoretical models or at least adjustments of existing ones. In the following three, in that respect, particularly interesting (sets of) experimental games are presented and discussed. In each case, first the game underlying the experiment will be presented and the standard game theoretic predictions derived. Thereafter, the behavioral regularities observed in the experiments will be discussed and compared to the standard predictions. Lastly, adjusted or new theoretical models inspired by deviations from standard theory will be presented.

\subsection{The guessing a number game}

The guessing game $\underline{\underline{44}}$ (aka beauty contest) was introduced to the experimental economics literature by Nagel ${ }^{45}$. In this simple game each participating player has to guess a number between 0 and 100 (inclusive). The person who chooses the number that is closed to the weighted average of $p$ times the average of all chosen numbers wins the game. In case there is more than one closest number a random device chooses one of them as the winner with equal probability. The winner receives a substantial predetermined reward, mostly money. Usually it is assumed that $0<p<1$, although there are also versions with $p>1$. For convenience, assume $p=1 / 2$ which 
is will also be the parameter of the experiment reported here. The game has the nice game theoretical feature that is solvable with iterated elimination of weakly dominated strategies. Assume that each player wants to win the game. The first step of reasoning is then that for $p=1 / 2$ nobody will choose a number strictly larger than 50, because irrespective of the others choices the weighted average is at most 50 and one can never win when choosing a number larger than 50. The second step involves the first-order rationality assumption that if every player reasons like that, the weighted average can never be larger than 25 and, hence, one should never choose a number strictly larger than 25. Again, considering that everybody will reason like that the third step implies never to choose a number strictly larger than 12.5. On the $t$-th iteration nobody should choose a number strictly larger than $\left(1 / t^{2}\right) 100$, which converges to 0 when $t$ grows beyond limit. Hence, infinite iteration of elimination of weakly dominated strategies leads to everybody choosing zero, which is also the unique Nash equilibrium of this game. Thus, under the assumption of common knowledge of rationality, that is that subjects are rational and believe that all other subjects are also rational and believe that all subjects believe that all other subjects are rations etc., all subjects should choose zero.

In order to allow for learning, in experiments the game is often played repeatedly for several rounds. Between rounds information is given about the actually chosen average number in the previous round. Figure 1 shows the results of a fully incentivized class room experiment during a psychology class at Maastricht University with more than 160 participants where the game was played for two rounds. The observed behavior in both rounds is representative for the original results $\frac{45}{}$, which also have been replicated several times with students $\frac{46,47}{4}$ but also with the general population via newspaper experiments. $\underline{48}$. In the first round, the average guess is 24.1 (median 18.5) and a large array of different numbers is observed. Only a few participants choose numbers larger than 50 and still not many numbers larger than 25, indicating that most participants used at least two iterations of reasoning, but also not many more. In the round 2 data (Figure 1(b) a clear learning process is feasible as the mass of chosen numbers shifts left giving an average of 10.2 (median 6). Now most participants choose numbers lower than 12.5 indicating that they used at least three iterations of reasoning. Repeating the game more often usually leads to further shifts of the distribution of chosen numbers to the left (see, e.g., reference $\left.\frac{45}{5}\right)$.

From the data it is obvious that participants do not immediately play the Nash equilibrium. These and equivalent results in similar games $\frac{49}{9}$ inspired the development of models of limited reasoning known as cognitive hierarchy and k-level models 50,51 . These two models differ in details but their basic idea is the same. Both assume that there are types of players who differ in depthof-reasoning. In the simplest version a level-0 type just chooses randomly, a level-1 type takes an 


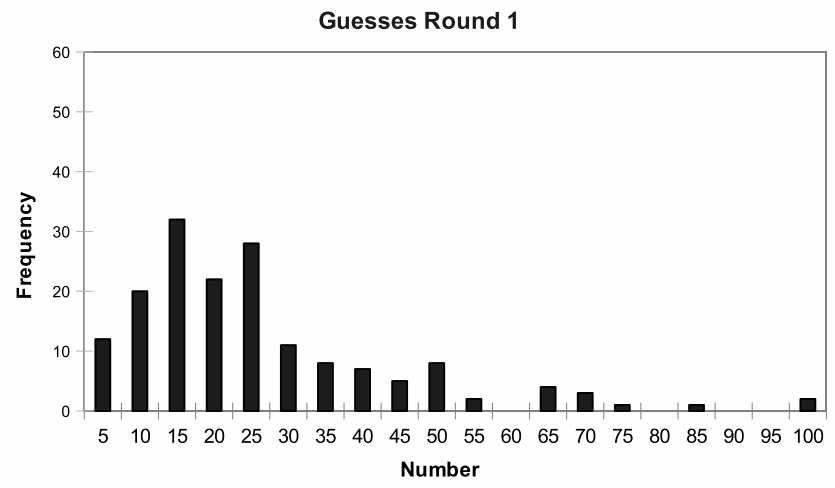

(a) Guessing game results - Round 1 (average guess: 24.1, median guess: $18.5, \mathrm{n}=166$ )

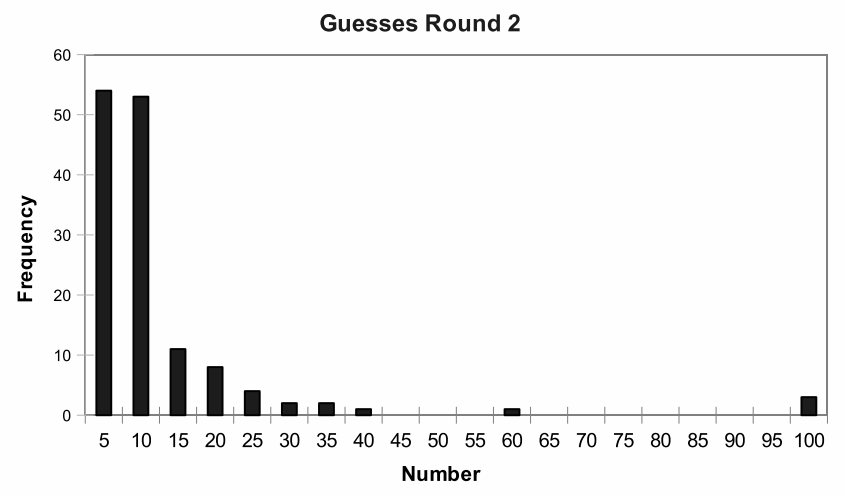

(b) Guessing game results - Round 2 (average guess: 10.2, median guess: $6, \mathrm{n}=165$ )

Figure 1: Guessing game results

optimal action under the assumption that the others are of level-0, a level-2 type takes an optimal action under the assumption that the others are of level-1, and so on. In applications it is often assumed that higher level types also make errors which can easily be integrated in the models. Calibrations of these models lead to predictions that are surprisingly consistent with the data observed in games of strategic reasoning, as the guessing game. Interestingly, the distribution of estimated types in the population of participants is relatively stable across different games and the depth-of-reasoning is seldomly higher than level-3, with most mass on level-1 and level2. Importantly, a level-k player is rational in the game theoretic sense but departs from Nash equilibrium reasoning in having a simple model of others. While these models organize that data for a given game quite well it is an open issue how well these models predict across games. But, this is ultimately an empirical issue and calls for experiments tackling this question. 


\subsection{The travelers' dilemma}

The story of the travellers' dilemma game ${ }^{52}$ goes as follows $\frac{53}{}$. During vacation two travelers purchase identical antiques which get lost on their return flight. To be eligible for compensation the airline asks both travelers to independently and simultaneously state their claims. To avoid excessive dishonest claims the airline stipulates some rules. The travelers can state any integer claim between USD 2 and USD 100 (inclusive) but will be paid only the smaller of the stated claims. Further, if the two claims differ, the traveler with the lower claim will receive a bonus of USD 2 while the traveler with the larger claim will have to pay a penalty of USD 2. From the joint perspective of both travelers it would be reasonable that both state USD 100, leaving each of them with the highest possible compensation. Note, however, that if traveler A assumes that traveler B states USD 100 she has an incentive to undercut by stating USD 99, because she would receive the bonus and end up with USD 101. Since the same reasoning applies to traveler B both will rather choose USD 99 instead of USD 100. Yet, if both travelers have arrived at that conclusion the same reasoning applies again leading to further undercutting until it becomes impossible. Hence, at the end both will claim USD 2, which are also the unique Nash equilibrium claims. When thinking about the game it seems implausible that the small bonus and penalty will drive real people's behavior all the way down to the Nash equilibrium. Yet, what if the bonus and penalty are substantial, say USD 60? Is it still unintuitive that the travelers will rather go for the secure low claim payment than for the uncertain high claim with a high potentially penalty?

Goeree and Holt $\underline{\underline{54}}$ conducted experiments where subjects played the travelers' dilemma game in pairs and had to choose claims between 80 and 200 (inclusive). In one treatment the bonus/penalty was low, $R=10$, in a second treatment it was intermediate, $R=25$, and in a third treatment it was high, $R=50$. In all treatments the unique Nash equilibrium is for both subjects to choose 80 for the reasons given above. The striking results are depicted in Figure 2(a). For a low bonus/penalty subjects were indeed largely able to resists the temptation of undercutting and chosen claims are at or very close to the maximum claim. This changes drastically for the high bonus/penalty treatment where a majority of choices is precisely at the lowest claim Nash equilibrium and only in a negligible number of cases high claims are chosen. The intermediate bonus/penalty treatments generates claims in-between these extremes. A theoretical modeling approach that has been successful in organizing such results is to allow for mistakes which likelihood is weighted by the potential losses induced by ones own mistakes and by the mistakes other players may make. The intuition is that if for a given strategy a mistake by the other player would lead to a larger loss than for another strategy than one will play the latter strategy with a higher likelihood. A similar reasoning holds for own mistakes and for the other players. Hence, players are still assumed to play best responses but are allowed to make 


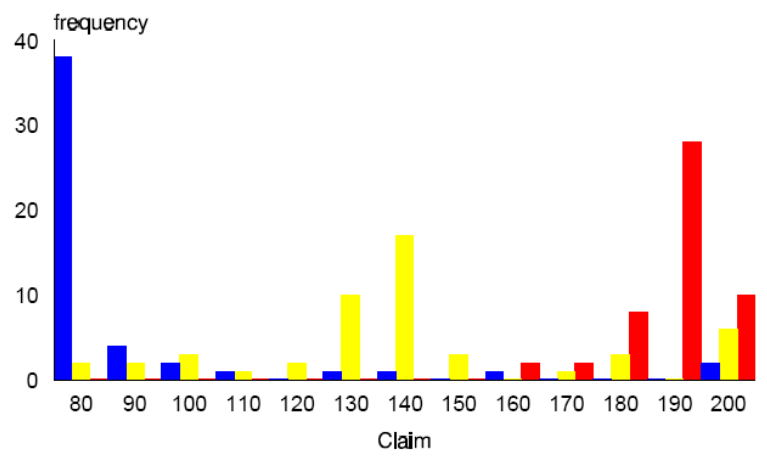

(a) Frequency of chosen claims for low (red), intermediate (yellow) and high (blue) bonus/penalty.

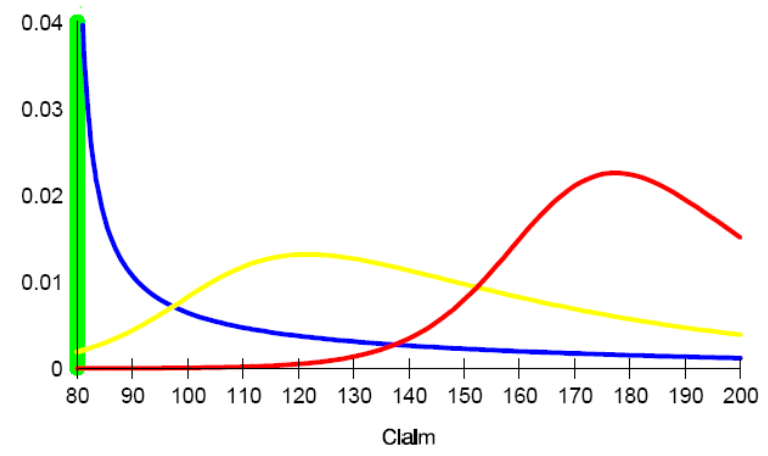

(b) Estimated densities of chosen claims for low (red), intermediate (yellow) and high (blue) bonus/penalty using logit QRE model; Nash equilibrium is at 80 .

Figure 2: Traveler's dilemma

Note: Copyright(1999) National Academy of Sciences, U.S.A. $\underline{54}$

mistakes with the likelihood of a mistake being inversely related to its severity. This idea of an 'equilibrium with noise' is formalized in the concept of Quantal Response Equilibrium $\underline{55}$ (QRE). The weight of the mistake in the calculation of the best response is the free parameter in this model which covers the full range from pure random choice to fully rational behavior. QRE is applied as logit-QRE to the travelers dilemma game in references $52,54,56$. Figure 2(b) shows the calculated densities of the chosen claims on the basis of logit QRE. Comparing actual choices and estimates shows that the logit QRE model captures the main features of the experimental data well. In particular, it reproduces the comparative statics effect for the different bonus/penalty treatments. For low bonus/penalty the probability mass is at the high end of the claims, while for high bonus/penalty it is at the low end. As for the actual data, for intermediate bonus/penalty most mass of the choice probabilities are in intermediate claim ranges.

QRE is also successfully applied to a range of other games $\underline{56}$ but can be criticized on conceptual and empirical grounds. Conceptually because QRE does not truly model bounded rational 
behavior, but - as the Nash equilibrium - relies on a fixed point argument, implicitly assuming common knowledge of noisy best response behavior and, hence, highly rational players. From this perspective QRE is an 'as-if' model that should be judged on basis of its success in reproducing actual behavior and not because it is a realistic model of human behavior. Empirically, it is vulnerable because for some games it errs consistently in the opposite direction from the observed behavior. $\frac{57}{\underline{5}}$

\subsection{Ultimatum, gift-exchange and trust games}

This last set of experiments to be discussed is on a class of games that are also known beyond experimental economics because they are useful for the study of social motives or social preferences. Indeed, the number of published experiments on these games is huge and it is impossible to fully survey them here. (For surveys or meta-analysis of experiments on the ultimatum game, gift-exchange and trust game see references $32,58,59$.) They are briefly discussed here because the results obtained in experiments on these games have been instrumental in the development of theoretical models of generalized preferences of fairness and reciprocity. The ultimatum game 60 is a simple bargaining game where a first mover (proposer) can make a proposal of how to share a given amount of money and a second mover (responder) can accept or reject the proposal. Upon acceptance the proposal is implemented. If the responder rejects both receive nothing. The unique subgame perfect Nash equilibrium is that the proposer demands the whole amount and the responder accepts. In the gift-exchange game $\frac{61,62}{2}$ a firm can offer wages to a worker who can upon acceptance exert effort which increases the firms revenues but decreases the workers earnings because effort is costly. Here the unique subgame perfect equilibrium stipulates that irrespective of the received wage the worker always chooses the lowest effort, the firm anticipates this and offers a contract with the lowest possible wage. The trust or investments game $\frac{63}{}$ is similar to the gift-exchange game. There a first mover (trustor) can sent an amount of money to the second mover (trustee). The sent amount is tripled and the trustee can - but does not have to - send back any of the received amount. In this game, in the unique subgame perfect Nash equilibrium the trustee keeps all the money received, the trustor anticipates that and does not send any money in the first place.

Perhaps not surprisingly, the standard game theoretic predictions are not borne out by the data. In ultimatum games proposers offer substantial amounts of money and responders reject positive but low offers. In the gift-exchange game firms offer higher than minimum wages and workers reciprocate with higher than minimum effort. In fact, there is a strong positive relationship between wages offered and effort chosen. Similarly, in trust games trustors regularly send positive amounts and trustees most of the time do not exploit their strong position but send 
money back. In response to these violations of predictions based on the standard selfish-money maximizing assumption a number of generalized preference models have been developed. These models can roughly be classified in outcome based $\underline{64-68}$ and intention based $\underline{69,70}$ models. Outcome based models assume that subjects dislike inequality or have a taste for efficiency. Intention

based models build on psychological game theory $\underline{71,72}$ and take the opportunities players have and their beliefs about the intentions of other players into account. For instance, a decision that leads to unequal earnings is always disliked in outcome based models but not so in intention based models if the player responsible for the outcome had no other choice or when the other choices would have led to even more unequal outcomes. There are also hybrid models $\frac{73,74}{7 e v e l o p e d}$ that try to merge both ideas.

Overall and on the aggregate level these models can organize the data quite well and there are even successful attempts to estimate inequality aversion in the general population using ultimatum game experiments $\frac{75}{}$. Yet, in organizing individual level data these models perform less well. Specifically, across different games the correlation of motives within-subjects is low $\underline{\underline{76}}$. A possible reason for this low correlation could be that people's considerations in situations where they have to make a trade-off between own earnings and the earnings of others are not one-dimensional as assumed in these models but are derived from mixed motives 37 . Clearly further developments of encompassing theoretical models and experimental tests of these models are necessary in order to converge to a decision model that captures the most important aspects of the decisions process in situations where social comparisons are important.

\subsection{More fields in experimental economics}

There is an extensive experimental economics literature in areas that are not touched upon here. For instance, the large and important literature on public good games with and without punishment is ignored. (For surveys see references $\frac{77,78}{78}$ and for recent studies going beyond the usual homogeneous groups implementation by introducing heterogeneity see references $\underline{79} \underline{-81}$.) Similarly, there are vivid experimental research activities on coordination games ${ }^{82}$, communication and learning ${ }^{32}$, auctions ${ }^{83,84}$, markets and industrial organization ${ }^{85}$, etc. Interesting is also the development of experimental research in an area that until now has proven to be quite immune to the insights generated by experimental research: macroeconomics. There is only a handful but slowly increasing number of published experimental studies dealing with macroeconomic questions, using so-called global games ${ }^{86}$, applying and testing general equilibrium theory ${ }^{87-92}$, investigating financial markets ${ }^{93}$, and examining monetary theory $\underline{\underline{94}}$. (For an overview see reference ${ }^{95}$.) 


\section{CONCLUSION}

Over the last thirty years experimental economics has developed from playing only a marginal role in economics research into a mature and widely accepted research branch in economics and beyond. Part of this success has to be attributed to the fact that experimental designs in economics are usually based on formal game theoretic models, which force the researcher to be clear and concise about her assumptions when formulating hypotheses. The formal models also provide useful guidelines regarding the importance of specific environmental variables and how changes in that variables are expected to affect the outcome variables of interest, which in turn allows causal inference. Economics experiments are, therefore, an ideal test-bed for falsifying theoretical models. Importantly, however, as much as economics experiments are useful for falsifying (elements of) existing theoretical models they are equally important for suggesting adaptations of existing models or even entirely new ways of thinking about how people make decisions in economic and strategic environments. The theory based nature of economics experiments also implies to large extent the two principles of experimental economics research: the use of task related (monetary) incentives and the norm of no deception. No deception is a prerequisite for drawing valid inferences because there must be no doubt that experimental subjects believe the rules they are told. Task related incentives are important because models often make predictions of change in behavior related to such incentives. It also allows to induce preferences over otherwise worthless objects. Further, these incentives can and have been used to measure trade-offs between monetary and non-monetary aspects of human motivation.

The interplay between theoretical modeling and experimental falsification will also play a major role in future experimental economics research. Currently, many alternative models of individual and social decision-making are on the market. Economics experiments are ideally suited to pit alternative models against each other. Further, new experimental designs will lead to new unexpected behavioral regularities which will in turn generate new decision-making models. In the future, there will also be an increasingly important role for economics experiments as tools of policy advice, because with experiments one can implement complex economic and social policy problems that are beyond theoretical analytical tractability. In addition, in experiments real peoples behavior is observed which seems an important precondition for offering useful policy advice. $.96,97$.

The success of economics experiments as a research method may also be measured by their application in other social sciences. Indeed, the relatively new research branch of neuroeconomics (aka decision neuroscience) may have not developed as successfully as it did without the tools provided by experimental economics. Experimental designs based on or inspired by economics experiments have been used in the study of neural correlates with cooperative behavior $\frac{98}{}$, 
trust $\underline{99}-101$, rejections in ultimatum games ${ }^{102,103}$, social preferences 104,105 , and strategic reasoning in guessing games ${ }^{106}$, among others. (For more examples and overviews of the application of experimental economics principles in neuroeconomics, see references $107-110$.) In sociology experimental economics methods are used for the study of trust $\stackrel{111,112}{ }$ and networks $\frac{113}{}$, in biology for investigating the evolution of pro-social behavior $\stackrel{114,115}{ }$, in psychiatry to study cooperation in patients with borderline disorder $\frac{116}{}$ and trust in patients with clinical paranoia $\frac{117}{}$, and in political science to study voting behavior $\underline{118,119}$ and legislative bargaining 120 .

\section{References}

1. Roth AE. Introduction to experimental economics. In Kagel JH, Roth AE, eds., The Handbook in Experimental Economics. Princeton University Press, Princeton, New Jersey, 1995, $3-109$.

2. Bernoulli D. Specimen theoriae novae de mensura sortis. comentarii academiae scientarium imperialis petropolitanae v, 175-192, 1738. english translation 1954 by l. sommer with footnotes by karl menger, exposition of a new theory on the measurement of risk. Econometrica $1738[1954], 22: 23-26$.

3. Bottom WP, Bontempo RN, Holtgrave DR. Experts, novices, and the St. Petersburg paradox: Is one solution enough? Journal of Behavioral Decision Making 1989, 2:113-121.

4. Cox JC, Sadiraj V, Vogt B, Dasgupta U, Is there a plausible theory for risky decisions? Experimental economics center working paper, Georgia State University, 2007.

5. Neugebauer T, Moral impossibility in the petersburg paradox: A literature survey and experimental evidence. Working paper, University of Luxembourg, 2010.

6. Weber EU. Risk attitude and preference. Wiley Interdisciplinary Reviews: Cognitive Science 2010, 1:79-88.

7. Bardsley N, Cubitt R, Loomes G, Moffatt P, Starmer C, Sudgen R, Experimental Economics: Rethinking the Rules. Princeton University Press, Princeton, 2010.

8. Edgeworth FY, Mathematical Psychics. Kelley, 1967 kelley edition edition, 1818.

9. Jevons S, The Theory of Political Economy. Macmillan, London, 1970 penguin edition edition, 1871.

10. Friedman M. The methodology of positive economics. In Essays in Positive Economics. Chicago University Press, Chicago, 1953, 3-43. 
11. Samulson PA, Nordhaus WD, Principles of Economics. McGraw-Hill Higher Education, New York, 12 edition, 1985.

12. Rosen HS, Gayer T, Public Finance. McGraw-Hill Higher Education, New York, 9 edition, 2010.

13. Samulson PA, Nordhaus WD, Principles of Economics. McGraw-Hill Higher Education, New York, 14 edition, 1992.

14. Thurstone LL. The indifference function. Journal of Social Psychology 1931, 2:139-167.

15. Chamberlain EE. An experimental imperfect market. Journal of Political Economy 1948, $56: 95-108$.

16. Sauermann H, Selten R. Ein oligopolexperiment. Zeitschrift für die gesamte Staatswissenschaft / Journal of Institutional and Theoretical Economics 1959, 115:427-471.

17. Siegel S, Fouraker LE, Bargaining and Group Decision Making: Experiments in Bilateral Monopoly. McGraw-Hill, New York, 1960.

18. Smith V. An experimental study of competitive market behavior. Journal of Political Economy 1962, 70:111-137.

19. Friedman JW. On experimental research in oligopoly. Review of Economic Studies 1969, $36: 399-415$.

20. Falk A, Heckman JJ. Lab experiments are a major source of knowledge in the social sciences. Science 2009, 326:535-538, doi:10.1126/science.1168244.

21. Nobelprizeorg, The sveriges riksbank prize in economic sciences in memory of alfred nobel 2002. http://www .nobelprize.org/nobel_prizes/economics/laureates/2002/, 2002.

22. Nobelprizeorg, The sveriges riksbank prize in economic sciences in memory of alfred nobel 2009. http://www.nobelprize.org/nobel_prizes/economics/laureates/2009/, 2009.

23. Ostrom E. Coping with the tragedy of the commons. Annual Review of Political Science 1999, 2:493-535.

24. Plott C, Equilibrium, equilibration, information and multiple markets: from basic science to institutional design. In Nobel Symposium on Behavioral and Experimental Economics.

25. Smith V. Experimental economics: induced value theory. American Economic Review 1976, $66: 274-279$. 
26. Friedman D, Cassar A, eds., Economics lab: an intensive course in experimental economics. Routledge, London and New York, 2004.

27. Kachelmeier SJ, Shehata M. Culture and competition: A laboratory market comparison between china and the west. Journal of Economic Behavior and Organization 1992, 19:145168.

28. Andreoni J, Miller J. Giving according to garp: An experimental test of the consistency of preferences for altruism. Econometrica 2002, 70:737-753.

29. Forsythe R, Horowitz JL, Savin N, Sefton M. Fairness in simple bargaining experiments. Games and Economic Behavior 1994, 6:347-369.

30. Hoffman E, McCabe K, Shachat K, Smith V. Preferences, property rights, and anonymity in bargaining games. Games and Economic Behavior 1994, 7:346-380.

31. Bolton GE, Katok E, Zwick R. Dictator game giving: Rules of fairness versus acts of kindness. International Journal of Game Theory 1998, 27:269-299.

32. Camerer C, Behavioral game theory: Experiments in strategic interaction. Princeton University Press, New York and Princeton, 2003.

33. Bardsley N. Dictator game giving: altruism or artefact? Experimental Economics 2008, $11: 122-133$.

34. List JA. On the interpretation of giving in dictator games. Journal of Political Economy 2007, 115:482-493.

35. Varian HR, Microeconomic Analysis. Norton, New York, 3 edition, 1993.

36. Engelmann D, Strobel M. Inequality aversion, efficiency, and maximin preferences in simple distribution experiments. American Economic Review 2004, 94:857-869.

37. Bolle F, Breitmoser Y, Heimel J, Vogel C. Multiple motives of pro-social behavior: Evidence from the solidarity game. Theory and Decision 2011:forthcoming.

38. Tausch F, Potters J, Riedl A, Preferences for redistribution and pensions: What can we learn from experiments? Meteor reseaerch memorandum, Department of Economics, Maastricht University, 2010.

39. Camerer CF, Hogharth RM. The effects of financial incentives in experiments: A review and capital-labor-production framework. Journal of Risk and Uncertainty 1999, 19:7-42. 
40. Hertwig R, Ortmann A. Experimental practices in economics: A challenge for psychologists? Behavioral and Brain Sciences 2001, 24:383 -403.

41. Ortmann A, Hertwig R. The costs of deception: evidence from psychology. Experimental Economics 2002, 5:111-131.

42. Jamison J, Karlan D, Schlechter L. To deceive or not deceive: the effect of deception on behavior in future laboratory experiments. Journal of Economic Behavior and Organization 2008, 68:477-488.

43. Kagel JH, Roth AE, eds., The handbook in experimental economics. Princeton University Press, Princeton, New Jersey, 1995.

44. Moulin H, Game Theory for Social Science. New York University Press, New York, 1986.

45. Nagel R. Unraveling in guessing games: An experimental study. American Economic Review 1995, 85:1313-1326.

46. Teck H, Camerer CF, Weigelt K. Iterated dominance and iterated best-response in experimental "p-beauty contests". American Economic Review 1998, 88:947-969.

47. Camerer CF, Ho T, Chong K. Sophisticated experience-weighted attraction learning and strategic teaching in repeated games. Journal of Economic Theory 2002, 104:137-188.

48. Bosch-Domenech A, Montalvo JG, Nagel R, Satorra A. One, two, (three), infinity, ... : Newspaper and lab beauty-contest experiments. American Economic Review 2002, 92:16871701.

49. Costa-Gomes MA, Crawford VP, Broseta B. Cognition and behavior in normal-form games: An experimental study. Econometrica 2001, 69:1193-1235.

50. Camerer CF, Ho TH, Chong JK. A cognitive hierarchy model of games. Quarterly Journal of Economics 2004, 119:861-898.

51. Crawford VP, Iriberri N. Level-k auctions: Can a nonequilibrium model of strategic thinking explain the winners curse and overbidding in private-value auctions? Econometrica 2007, $75: 1721-1770$.

52. Capra M, Goeree JK, Gomez R, Holt CA. Anomalous behavior in a traveler's dilemma? American Economic Review 1999, 89:678-690.

53. Basu K. The traveler's dilemma: Paradoxes of rationality in game theory. American Economic Review 1994, 84:391-395. 
54. Goeree JK, Holt CA. Stochastic game theory: for playing games, not just for doing theory. Proceedings of the National Academy of Sciencies USA 1999, 96:10564-10567.

55. McKelvey RD, Palfrey TR. Quantal response equilibria for normal form games. Games and Economic Behavior 1995, 10:6-38.

56. Goeree JK, Holt CA. Ten little treasures of game theory and ten intuitive contradictions. The American Economic Review 2001, 91:1402-1422.

57. Crawford VP, Costa-Gomes MA, Iriberri N, Strategic thinking. Technical report, Department of Economics, University of Oxford, 2010, mimeo.

58. Oosterbeek H, Sloof R, van de Kuilen G. Cultural differences in ultimatum game experiments: Evidence from a meta-analysis. Experimental Economics 2004, 7:171-188, doi: 10.1023/B:EXEC.0000026978.14316.74.

59. Fehr E, Goette L, Zehnder C. A behavioral account of the labor market: The role of fairness concerns. Annual Review of Economics 2009, 1:355-384.

60. Güth W, Schmittberger R, Schwarze B. An experimental analysis of ultimatum bargaining. Journal of Economic Behavior and Organization 1982, 3:367-388.

61. Fehr E, Kirchsteiger G, Riedl A. Does fairness prevent market clearing? an experimental investigation. Quarterly Journal of Economics 1993, 108:437-459.

62. Fehr E, Kirchsteiger G, Riedl A. Gift exchange and reciprocity in competitive experimental markets. European Economic Review 1998, 42:1-459.

63. Berg J, Dickhaut J, McCabe K. Trust, reciprocity, and social history. Games and Economic Behavior 1995, 10:122-145.

64. Fehr E, Schmidt K. A theory of fairness, competition, and cooperation. Quarterly Journal of Economics 1999, 114:817-868.

65. Bolton G, Ockenfels A. ERC: A theory of equity, reciprocity, and competition. American Economic Review 2000:166-193.

66. Charness G, Rabin M. Understanding social preferences with simple tests. Quarterly Journal of Economics 2002, 117:817-869.

67. Cox JC, Friedman D, Gjerstad S. A tractable model of reciprocity and fairness. Games and Economic Behavior 2007, 59:17-45. 
68. Cox JC, Friedman D, Sadiraj V. Revealed altruism. Econometrica 2008, 76:31-69.

69. Rabin M. Incorporating fairness into game theory and economics. American Economic Review 1993, 83:1281-1302.

70. Dufwenberg M, Kirchsteiger G. A theory of sequential reciprocity. Games and Economic Behavior 2004, 47:268-298.

71. Geanakoplos J, Pearce D, Stacchetti E. Psychological games and sequential rationality. Games and Economic Behavior 1989, 1:6079.

72. Battigalli P, Dufwenberg M. Dynamic psychological games. Journal of Economic Theory 2009, 144:1-35.

73. Levine DK. Modeling altruism and spitefulness in experiments. Review of Economic Dynamics 1998, 1:593-622.

74. Falk A, Fischbacher U. A theory of reciprocity. Games and Economic Behavior 2006, 54:293-315.

75. Bellemare C, Kröger S, van Soest A. Measuring inequity aversion in a heterogeneous population using experimental decisions and subjective probabilities. Econometrica 2008, 76:815839.

76. Blanco M, Engelmann D, Normann HT. A within-subject analysis of other-regarding preferences. Games and Economic Behavior 2011, 72:321 - 338, doi:10.1016/j.geb.2010.09.008.

77. Gächter S, Herrmann B. Reciprocity, culture and human cooperation: previous insights and a new cross-cultural experiment. Philosophical Transactions of the Royal Society B: Biological Sciences 2009, 364:791-806, doi:10.1098/rstb.2008.0275.

78. Chaudhuri A. Sustaining cooperation in laboratory public goods experiments: a selective survey of the literature. Experimental Economics 2011, 14:47-83.

79. Reuben E, Riedl A. Cooperation and punishment in privileged groups. Journal of Conflict Resolution 2009, 53:72-93.

80. Reuben E, Riedl A, Enforcement of contribution norms in public good games with heterogeneous populations. Discussion paper (revised version), Maastricht University, 2011.

81. Nikiforakis N, Noussair CN, Wilkening T, Normative conflict and feuds: The limits of self-enforcement. Technical report, University of Melbourne, 2011. 
82. Devetag G, Ortmann A. When and why? A critical survey on coordination failure in the laboratory. Experimental Economics 2007, 10:171-178.

83. Kagel JH. Auctions: A survey of experimental research. In Kagel JH, Roth AE, eds., The Handbook in Experimental Economics. Princeton University Press, Princeton, New Jersey, $1995,501-585$.

84. Kagel JH, Levin D. auctions (experiments). In Durlauf SN, Blume LE, eds., The New Palgrave Dictionary of Economics. Palgrave Macmillan, Basingstoke, 2008.

85. Hinloopen J, Normann HT, eds., Experiments and Competition Policy. Cambridge University Press, Cambridge, 2009.

86. Heinemann F. Exchange rate attack as a coordination game: Theory and experimental evidence. Oxford Review of Economic Policy 2002, 18:462-478.

87. Noussair CN, Plott C, Riezman R. An experimental investigation of the patterns of international trade. American Economic Review 1995, 85:462-491.

88. Noussair CN, Plott C, Riezman R. Production, trade and exchange rates in large experimental economies. European Economic Review 2007, 51:46-76.

89. Lei V, Noussair CN. Equilibrium selection in an experimental macroeconomy. Southern Economic Journal 2007, 74:448-482.

90. Capra CM, Tanaka T, Camerer CF, Feiler L, Sovero V, Noussair CN. The impact of simple institutions in experimental economies with poverty traps. Economic Journal 2009, 119:977-1009.

91. Riedl A, Winden van F. An experimental investigation of wage taxation and unemployment in closed and open economies. European Economic Review 2007, 51:871-900.

92. Riedl A, Winden van F. Input versus output taxation in an experimental international economy. European Economic Review in press.

93. Heinemann F. Understanding financial crises: The contribution of experimental economics. Annals of Economics and Statistics in press.

94. Duffy J. Monetary theory in the laboratory. Federal Reserve Bank of St. Louis Review 1998, $80: 9-26$.

95. Duffy J, Macroeconomics: A survey of laboratory research. Working paper, University of Pittsburgh, 2008. 
96. Normann HT, Ricciuti R. Experiments for economic policy making. Journal of Economic Surveys 2009, 23:407-432.

97. Riedl A. Behavioral and experimental economics do inform public policy. FinanzArchiv / Public Finance Analysis 2010, 66:65-95.

98. McCabe K, Houser D, Ryan L, Smith V, Trouard T. A functional imaging study of cooperation in two-person reciprocal exchange. Proceedings of the National Academy of Sciences 2001, 98:11832-11835.

99. Kosfeld M, Heinrichs M, Zak PJ, Fischbacher U, Fehr E. Oxytocin increases trust in humans. Nature 2005, 435:673-676.

100. King-Casas B, Tomlin D, Anen C, Camerer CF, Quartz SR, Montague PR. Getting to know you: Reputation and trust in a two-person economic exchange. Science 2005, 308:78-83.

101. Krueger F, McCabe K, Moll J, Kriegeskorte N, Zahn R, Strenziok M, Heinecke A, Grafman J. Neural correlates of trust. Proceedings of the National Academy of Sciences 2007, 104:20084-20089.

102. Sanfey AG, Rilling JK, Aronson JA, Nystrom LE, Cohen JD. The neural basis of economic decision making in the ultimatum game. Science 2003, 300:1755-1758.

103. Knoch D, Pascual-Leone A, Meyer K, Treyer V, Ernst F. Diminishing reciprocal fairness by disrupting the right prefrontal cortex. Science 2006, 314:829832.

104. Fliessbach K, Weber B, Trautner P, Dohmen T, Sunde U, Elger CE, Armin F. Social comparison affects reward-related brain activity in the human ventral striatum. Science 2007, 318:1305-1308.

105. Tricomi1 E, Rangel A, Camerer CF, O'Doherty JP. Neural evidence for inequality-averse social preferences. Nature 2010, 463:1089-1091.

106. Coricelli G, Nagel R. Neural correlates of depth of strategic reasoning in medial prefrontal cortex. Proceedings of the National Academy of Sciences 2009, 106:9163-9168.

107. Smith DV, Huettel SA. Decision neuroscience: neuroeconomics. Wileys Interdisciplinary Reviews: Cognitive Science 2010, 1:854-871.

108. Glimcher PW, Foundations of Neuroeconomic Analysis. Oxford University Press, Oxford, 2011. 
109. Sanfey AG. Social decision-making: Insights from game theory and neuroscience. Science 2007, 318:598-602.

110. Fehr E, Camerer C. Social neuroeconomics: the neural circuitry of social preferences. Trends in Cognitive Sciences 2007, 11:419-426.

111. Cook KS, Yamagishi T, Cheshire C, Cooper R, Matsuda M, Mashima R. Trust building via risk taking: A cross-societal experiment. Social Psychology Quarterly 2005, 68:121-142.

112. Buskens V, Raub W, van der Veer J. Trust in triads: An experimental study. Social Networks 2010, 32:301-312.

113. Corten R, Buskens V. Co-evolution of conventions and networks: An experimental study. Social Networks 2010, 32:4 - 15, doi:10.1016/j.socnet.2009.04.002.

114. Nowak MA, Sigmund K. Evolution of indirect reciprocity. Nature 2005, 437:1291-1298.

115. Ule A, Schram A, Riedl A, Cason TN. Indirect punishment and generosity toward strangers. Science 2009, 326:1701-1704.

116. King-Casas B, Sharp C, Lomax-Bream L, Lohrenz T, Fonagy P, Montague PR. The rupture and repair of cooperation in borderline personality disorder. Science 2008, 321:806-810.

117. Fett AK, Shergill S, Riedl A, Strobel M, Gromann P, Krabbendam L. To trust or not to trust: The dynamics of social interaction in psychosis. Brain in press.

118. Grosser J, Schram A. Neighborhood information exchange and voter participation: An experimental study. American Political Science Review 2006, 100:235-248.

119. Morton RB, Williams KC. Experimentation in political science. In Box-Steffensmeier JM, Brady HE, Collier D, eds., The Oxford Handbook of Political Methodology. Oxford University Press, Oxford, 2008, 339-356.

120. Fréchette GR, Kagel JH, Lehrer SF. Bargaining in legislatures: An experimental investigation of open versus closed amendment rules. American Political Science Review 2003, $97: 221-232$. 